\title{
Bracket Structure Stress Analysis of Rotating Construction Cable-stayed Bridge of Thousands of Tons
}

\author{
Lifeng Wang, Erqiang Wang, and Dongpo He ${ }^{*}$
}

Northeast Forestry University, Harbin 150040, China

\begin{abstract}
Based on the rotating construction cable-stayed bridge of thousands of tons, dynamic simulation of bracket structure in rotating construction was analyzed with ANSYS finite element software. The result shows that with the common influence of gravity, traction and prestress, the overall bracket structure presents compressive stress mainly of stress state. Traction force of the impact is not big, considering alone effect of traction, the whole stress level of bracket structure is very low. Under the effect of prestress, bracket structure presents a huge pressure stress in horizontal direction to prevent accidental tilt in the rotating process, and parts of the steel bundle should be removed after the rotation.
\end{abstract}

Keywords: Analysis of forces, cable-stayed bridge, corbel, rotation construction,

\section{INTRODUCTION}

Structure capacity analysis can optimize the urban bridge construction [1]. As an important structure of Suifen River swivel cable-stayed bridge, bracket structure is especially the big volume structure between pile cap and main pier, which is different from the common form. It is necessary to calculate and analyze the key parts of the rotational structure [2]. Bracket structure is not only the bearing structure of the whole bridge, but also the rotating device to realize rotation the whole bridge. So it is vital to clear the stress state and influence factors of the bracket to provide references for the design and construction. The bracket structure of Suifen River bridge is shown in Fig. (1).

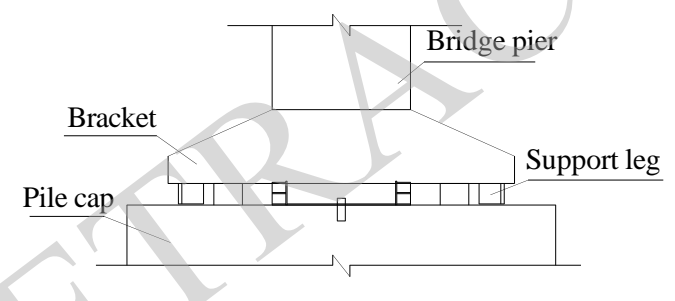

Fig. (1). The bracket structure of Suifen River bridge.

\section{PROJECT SUMMARY}

Suifen River bridge is a prestressed concrete cable-stayed bridge with single tower and single cable plane, whose span is $100 \mathrm{~m}+100 \mathrm{~m}$. It adoptes horizontal rotation construction with single point flat hinge. The weight of horizontal rotation entity reached $1.4 \times 10^{4}$ t. Suifen River bridge has single-box and three-room box girder, the width of deck is $23.5 \mathrm{~m}$ andthe height of the girder is $1.98 \mathrm{~m}$. The bridge tower is $61 \mathrm{~m}$ high with rectangular cross section and 18 pairs of staycables. The bridge structure diagram is shown in Fig. (2).

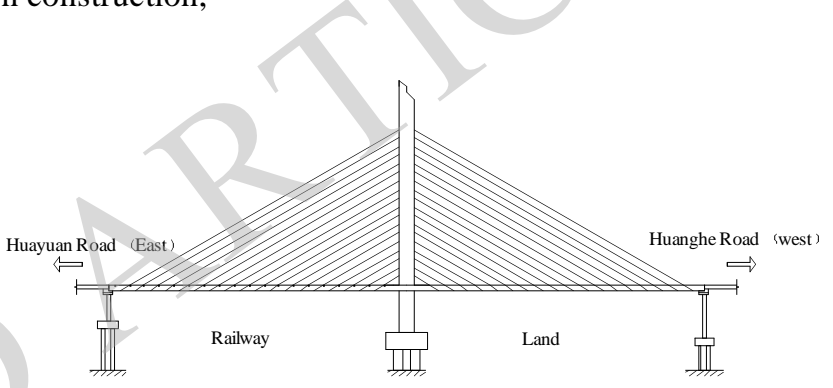

Fig. (2). The bridge structure diagram.

\section{BASIC ASSUMPTIONS OF THE STRUCTURE ANALYSIS}

Rotating construction cable-stayed bridges are mostly rotation system in balance [3]. Firstly, hypothesis was made for the specific analysis of various factors on the bracket stress influence in the rotating process.

(1) Ignore the changes of air temperature, namely the top and low edge of the girder has constant temperature.

(2) The properties of lubricating material are unchanged [4]. The contact surface between upper and lower rotary is smooth and flat. The main beam is stable in the rotating progress.

(3) The rotating speed is constant. Ignore the speed change on the influence of main girder. Namely, the angular acceleration is not considered.

\section{EQUIVALENT ELASTIC MODULUS CALCU- LATION}

The bracket in the project is prestressed concrete structure, which not only bears the $1.40 \times 10^{4} \mathrm{t}$ weight of the upper but also ensures the gap between steel tube concrete support leg and pile caps cannot produce bigger change. In the rotating progress the support leg is an effective temporary support, and an effective insurance device. The distance between the support leg and pile caps is not appropriate no matter big or small. The most suitable distance is confirmed 
$2 \mathrm{~cm}$ via many strict reasonings. In the rotating construction process, there distributed a large number of reinforcement in the bracket to ensure all kinds of stresses be satisfied with the standard requirement when the bracket is under the tensile stress.

A large number of reinforcement is not convenient for ANSYS simulation, so the equivalent modulus of elasticity of the bracket is calculated with Docter Bridge software. $1.40 \times 10^{4} \mathrm{t}$ pressure was applied to both plain concrete bracket structure and reinforced concrete bracket, and the equivalent modulus of elasticity was got through deformation ratio. The results are shown in Table $\mathbf{1}$.

Table 1. The equivalent modulus of elasticity of the bracket.

\begin{tabular}{|c|c|c|c|}
\hline Model & Load/t & $\begin{array}{c}\text { Equivalent modulus of } \\
\text { elasticity /MPa }\end{array}$ & $\begin{array}{c}\text { Deformation } \\
\text { /m }\end{array}$ \\
\hline \hline $\begin{array}{c}\text { Plain con- } \\
\text { crete }\end{array}$ & $1.40 \mathrm{e} 4$ & $3.50 \mathrm{e} 4$ & $5.32 \mathrm{e}-5$ \\
\hline $\begin{array}{c}\text { Reinforced } \\
\text { concrete }\end{array}$ & $1.40 \mathrm{e} 4$ & $4.20 \mathrm{e} 4$ & $4.48 \mathrm{e}-5$ \\
\hline
\end{tabular}

As is shown in Table 1, because of the arrangement of a large number of steel, the equivalent modulus of elasticity of the bracket is increased to $4.20 \mathrm{e} 4 \mathrm{MPa}$, which provides premise for more accurate calculation.

\section{DYNAMIC SIMULATION ANALYSIS OF BRACKET}

When analyze the bracket on dynamic simulation, the concrete and transitional units were respectively adopted solid65, solid95 unit [5]. The force conditions and deformation of the bracket in the construction process are analyzed [6]. The equivalent modulus of elasticity of the concrete adopts 4.2e4 MPa. As is shown in Fig. (3), the loading of prestressed steel adoptes initial strain form. As is shown in Fig. (4), the rotating simulation of bridge is to provide the horizontal reverse traction on both sides of the bracket along the height direction. The stress situation of the bracket under the traction is shown from Fig. (5) to Fig. (8).

Under the common function of gravity, bracket prestressing force and traction, the stress state of the bracket structure mainfests as compressive stress in both horizontal and vertical direction. From the above analysis, the maximum transverse compressive stress is $2.94 \mathrm{MPa}$, the maximum vertical compressive stress is $4.04 \mathrm{MPa}$. Both compressive stresses are mainly caused by weight of the whole bridge. Due to the direct contact between bracket bearing area and main pier, bottom vertical compressive stress of the bracket is bigger.

From Fig. (5) to Fig. (8), some units have exceeded the limits. The bracket element meshed with transitional units appeares large deviation in individual units on stress. The maximum vertical tensile stress is $-6.80 \mathrm{MPa}$, the maximum horizontal tensile stress is $-2.94 \mathrm{MPa}$, which exceed the ultimate tensile strength of C50 concrete. The overstressing distribution is shown in Fig. (9) and Fig. (10).

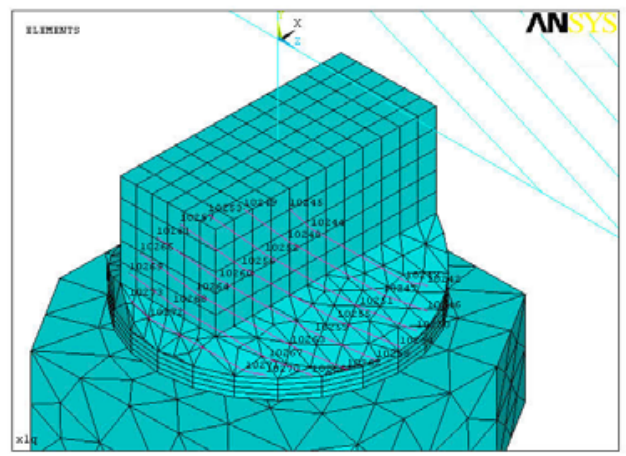

Fig. (3). Prestressed steel of the bracket.

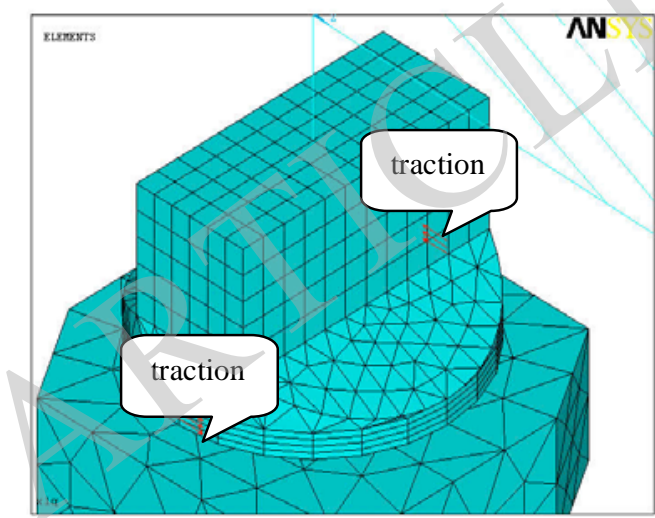

Fig. (4). The loading of traction on the bracket.

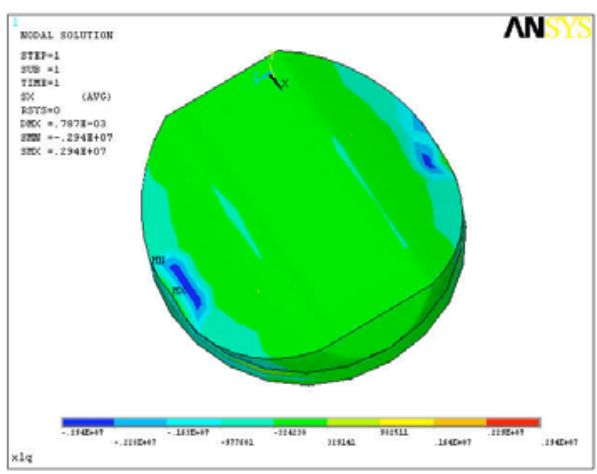

Fig. (5). Transverse stress on the top of the bracket.

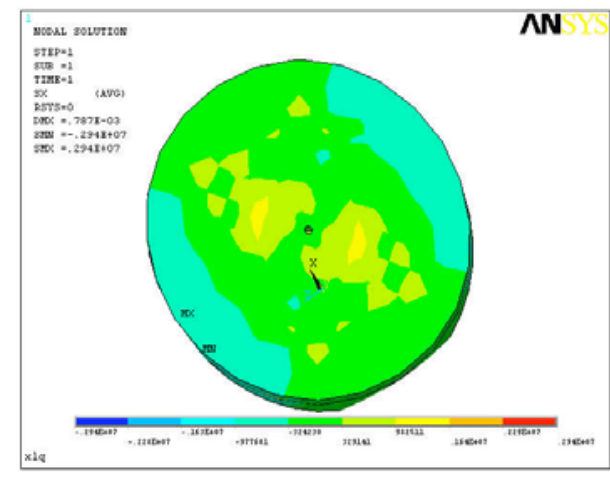

Fig. (6). Transverse stress on the bottom of the bracket. 


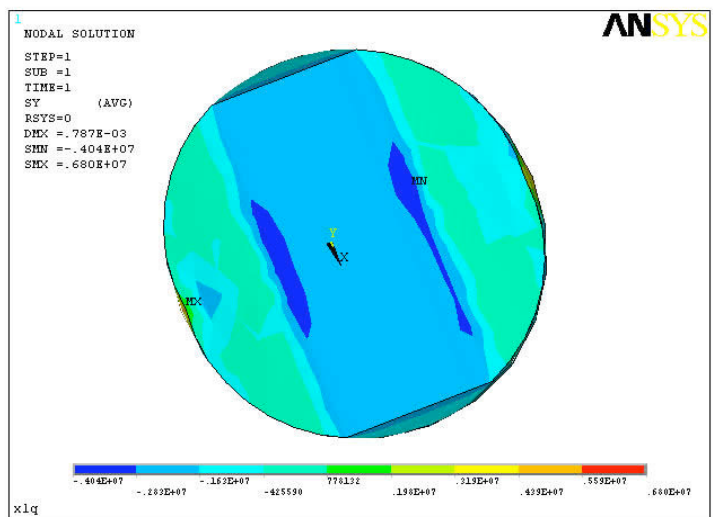

Fig. (7). Vertical stress on the top of the bracket.

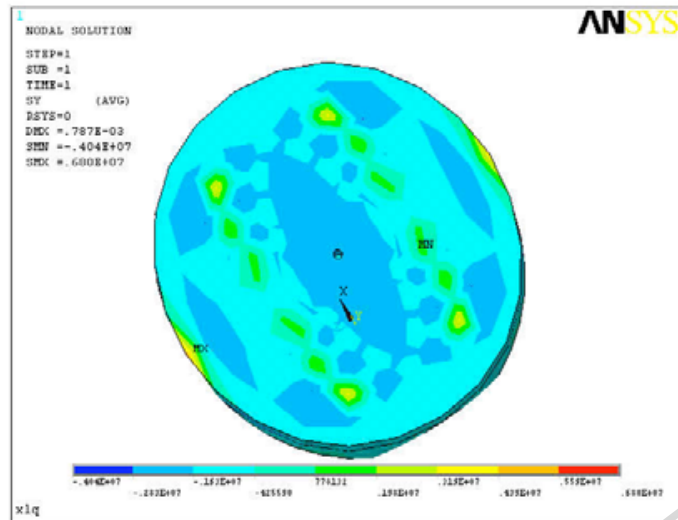

Fig. (8). Vertical stress on the bottom of the bracket.

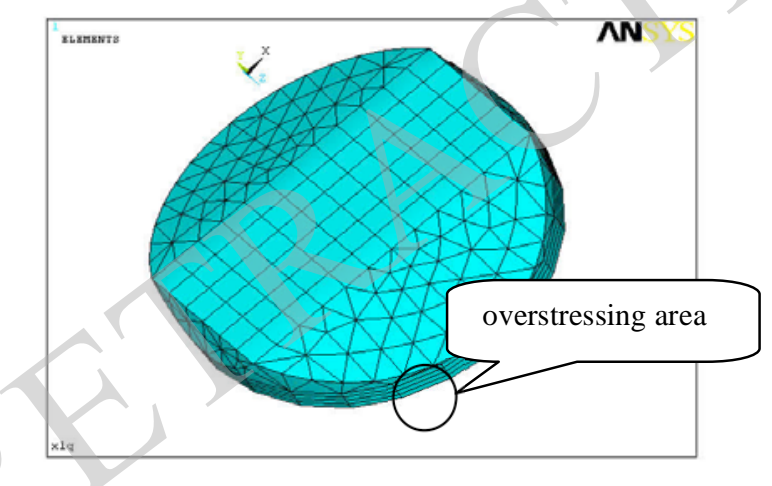

Fig. (9). Overstressing area.

The overstressing area is ignored due to it is too small. The ANSYS model shows that stress result is the average stress of adjacent units with common node, and this paper chooses the unit with the biggest node stress in the overstressing unit. The maximum tension stress $-2.94 \mathrm{MPa}$ appears in Fig. (10).

The bracket is a large volume concrete structure of $6.3 \mathrm{~m}$ bottom radius, which equips with plenty of prestressed reinforcement and ordinary reinforced. The bracket appears compressive stress and no transfinite situation under the common function of gravity, traction and prestress.

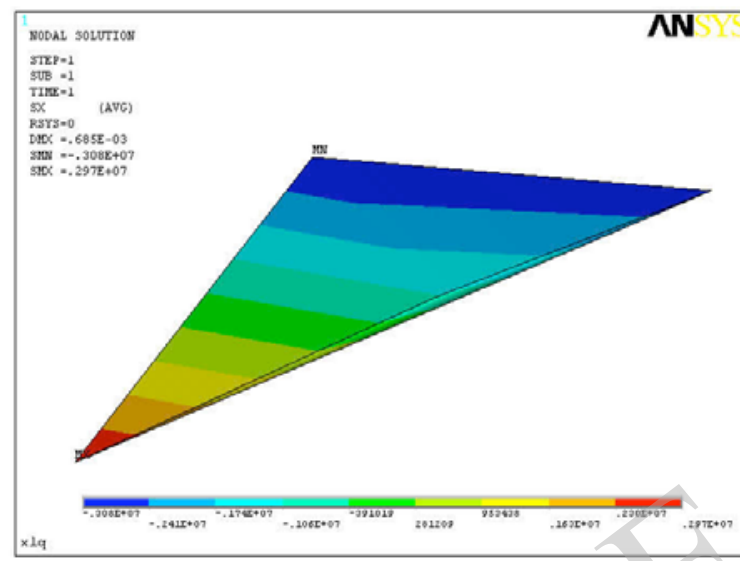

Fig. (10). Horizontal overstressing unit.

\subsection{Prestressed Effects on the Bracket Structure Stress Influence}

The bracket uses $\varphi 15.24$ high strength and low relaxation strand as prestressed steel, there are arranged 16 strands uniformly in the bottom of the bracket along the bridge longitudinal direction. In this paper the 16 strands are merged into eight beams for analysis facilitation, and the tension control stress is $1395 \mathrm{MPa}$. Under the action of prestress, longitudinal stress of the bracket is shown in Fig. (11). When the prestressing effect is ignored, longitudinal horizontal stress of the bracket is shown in Fig. (12).

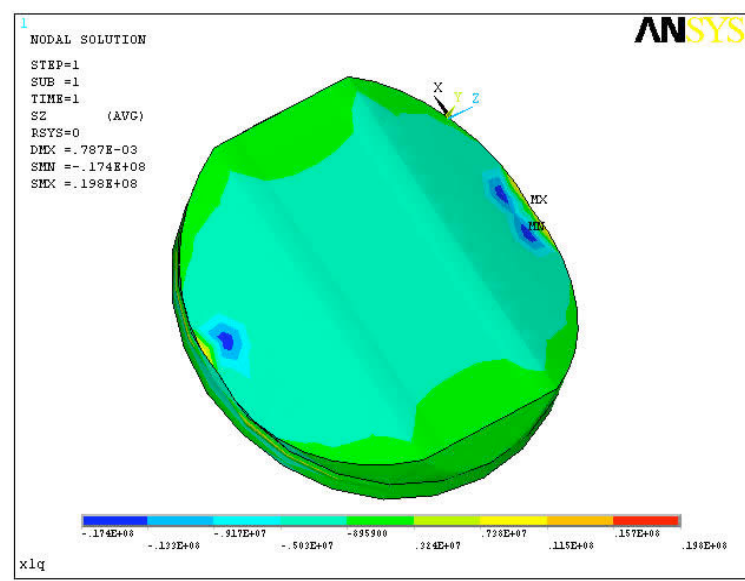

Fig. (11). Horizontal stress on the top of the bracket (bridge longitudinal direction).

It can be seen from Fig. (11) and Fig. (12), the maximum longitudinal compressive stress is $17.4 \mathrm{MPa}$ when the prestressed is considered. The maximum longitudinal compressive stress is $1.10 \mathrm{MPa}$ when the prestressed is ignored. So the big longitudinal compressive stress in the bracket is caused by the prestressed.

When compare Fig. (5) with Fig. (11), the compressive stress contrast data can be got, as is shown in Table $\mathbf{2}$. 


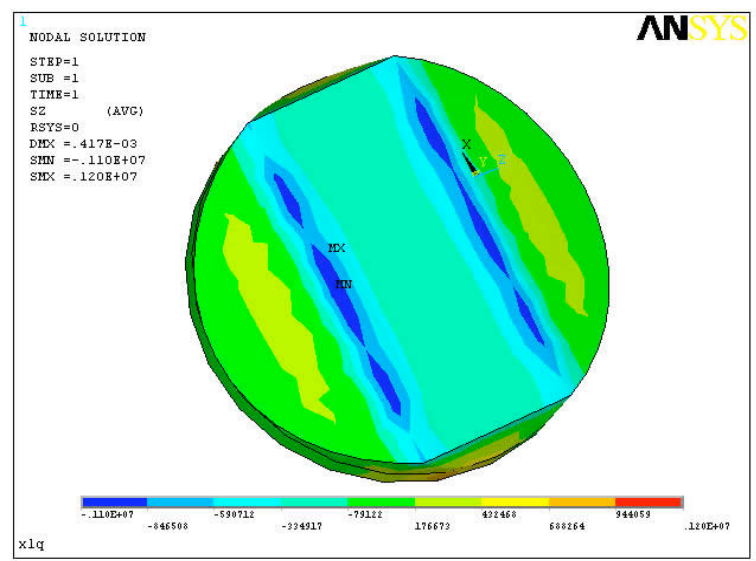

Fig. (12). Horizontal stress on the top of the bracket (no prestressed).

Table 2. The contrast between transverse and longitudinal stress of the bracket (MPa).

\begin{tabular}{|c|c|c|c|}
\hline Content & Transverse stress & $\begin{array}{c}\text { Longitudinal } \\
\text { stress }\end{array}$ & Ratio \\
\hline \hline Maximum value & 2.94 & 17.4 & 0.169 \\
\hline General value & 0.76 & 5.03 & 0.151 \\
\hline
\end{tabular}

Note: General value is determined according to the stress in the wide range area of the same color.

Table 2 shows that the ratios of transverse stress and longitudinal stress of the bracket are respectively 0.169 and 0.151 . Both ratios are very close to the poisson's ratio 0.1667 which appears in ANSYS. So the poisson effect also obtains a good proof in this model.

Due to the existence of the prestressed, the bracket reserve more pressure stress in horizontal direction, the accidental incline can be prevented in the process of rotation. The contact between support legs and pile caps causes tensile stress in the bottom of the bracket. If the bridge appears accidental incline, that will be too easy to lead to cracking on the bottom of the bracket structure. Therefore in the process of rotation, there arranges four groups of steel tube concrete support legs on the bottom where is easy to incline to avoid accidents.

After the rotation, the bracket mainly plays a supporting role, so there is no need to keep the brackets under a high pressure level in the long term. In the construction of Suifen River cable-stayed bridge, the bracket structure prestressed tensioning was applied in the front of rotation. The pipe will not grout and the steel beams of the part will be dismantled after the rotation.

After rotation, the bracket horizontal stress unconsidered traction role is shown in Fig. (13) and Fig. (14).

Through the comparation of Table 2, Fig. (13) and Fig. (14), horizontal compressive stress state before and after the rotation is got, as is shown in Table $\mathbf{3}$.

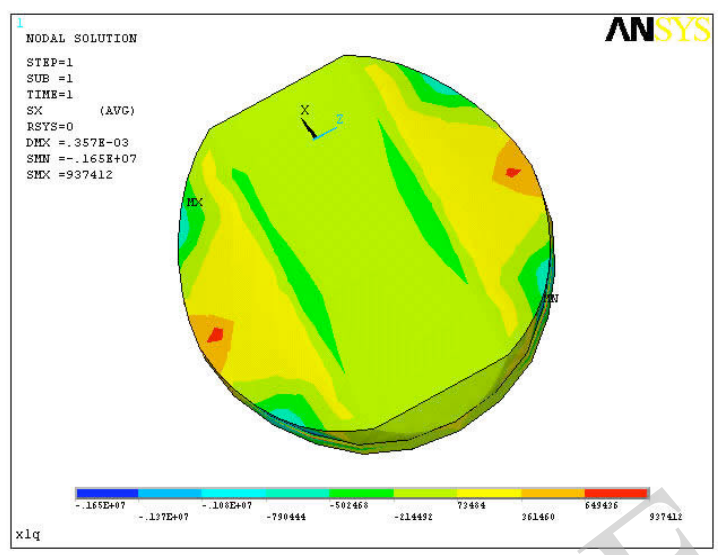

Fig. (13). Bracket horizontal stress after rotation (bridge transverse direction).

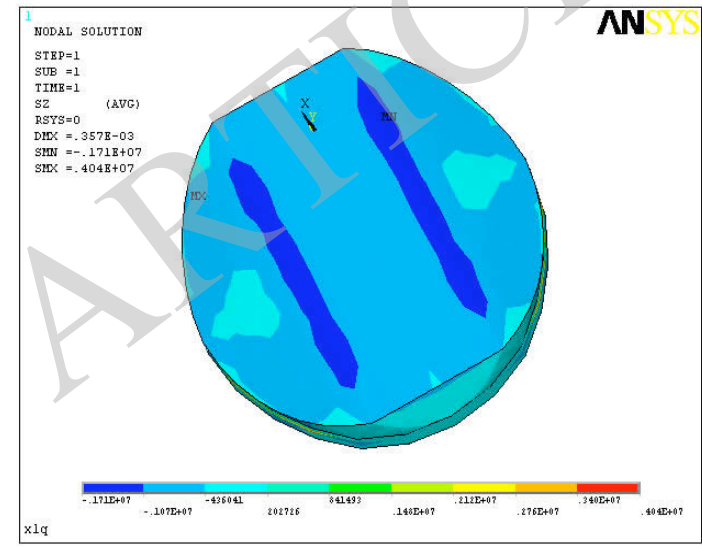

Fig. (14). Bracket horizontal stress after rotation (bridge longitudinal direction).

Table 3. Horizontal compressive stress comparison in rotation (MPa).

\begin{tabular}{|c|c|c|c|c|}
\hline \multirow{2}{*}{ Content } & \multicolumn{2}{|c|}{ Transverse direction } & \multicolumn{2}{c|}{ Longitudinal direction } \\
\cline { 2 - 5 } & Rotating & $\begin{array}{c}\text { After } \\
\text { rotation }\end{array}$ & Rotating & $\begin{array}{c}\text { After rota- } \\
\text { tion }\end{array}$ \\
\hline \hline Maximum & 2.94 & 1.65 & 17.4 & 1.71 \\
\hline Minimum & 0.76 & 0.21 & 5.03 & 1.07 \\
\hline
\end{tabular}

Note: General value is as same as Table $\mathbf{2}$.

Table 3 indicates that horizontal compressive stress will decrease after the part prestress dismantled. The compressive stress state of the bracket is suit for long-term bearing. Poisson's ratio is hard to reflect through the comparison between horizontal and longitudinal stress after rotation.

\subsection{Traction Effects on the Bracket Structure Stress In- fluence}

The key of the rotation of cable-stayed bridge is the continuous traction of the jack. The traction is loaded through the steel strand distributed in the bracket, the 
analysis below consider the traction only to describe the traction effects more immediately. The analysis results is shown in Fig. (15) to Fig. (18).

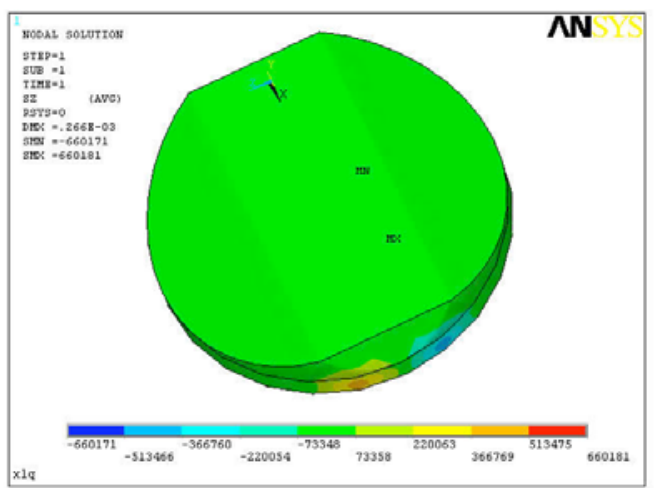

Fig. (15). Horizontal normal stress on bracket top (longitudinal direction).

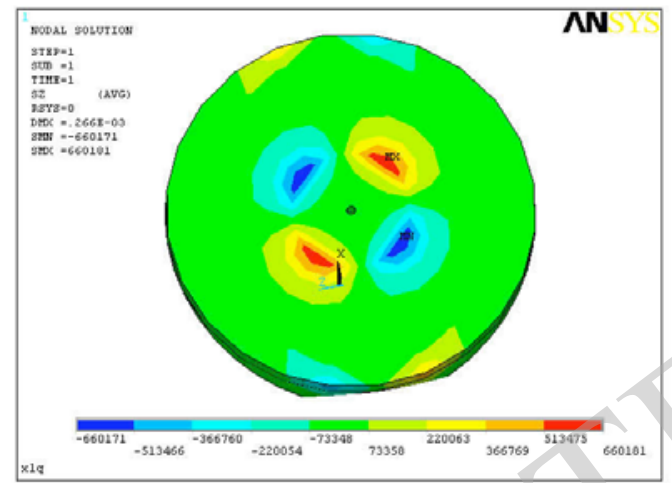

Fig. (16). Horizontal normal stress on bracket bottom (longitudinal direction).

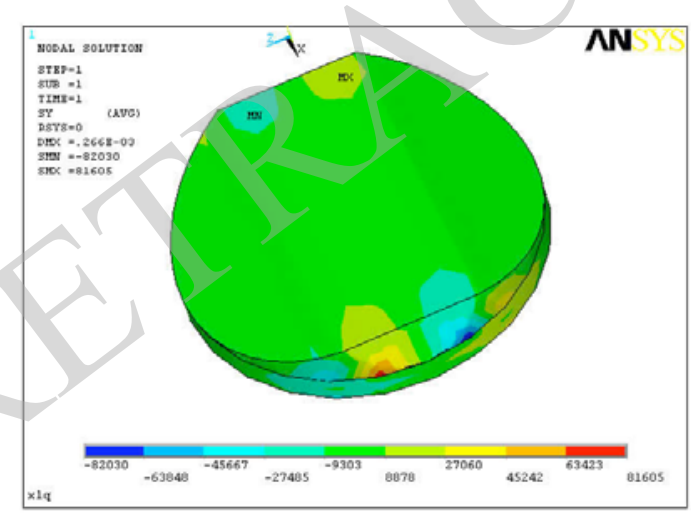

Fig. (17). Vertical stress on bracket top.

As is shown from Fig. (15) to Fig. (18), the stress state of the bracket is effected not obviously. The whole stress level is low. There are some local stress concentration in Fig. (15), Fig. (16) and Fig. (18). The maximum tensile stress is -0.41 $\mathrm{MPa}$, the maximum compressive stress is $-0.41 \mathrm{MPa}$. As is shown in Fig. (19), the bottom of the bracket is consolidated with the over span. The friction prevents the rotation of the bridge so as to result in the stress concentration on the bottom of the bracket.

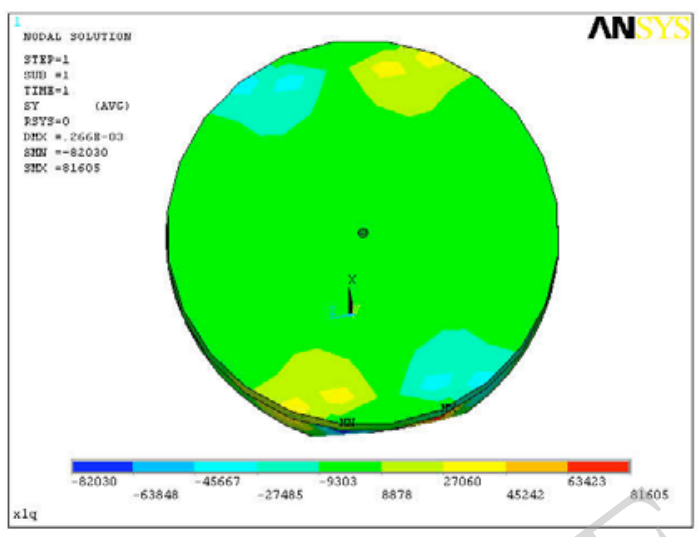

Fig. (18). Vertical stress on bracket bottom.

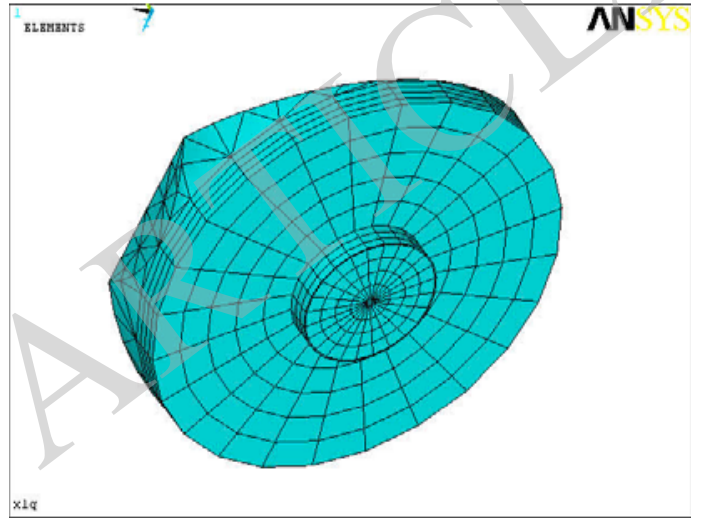

Fig. (19). Structure chart of bottom of the bracket.

The transformation of the bracket under the traction is shown in Fig. (20) and Fig. (21).

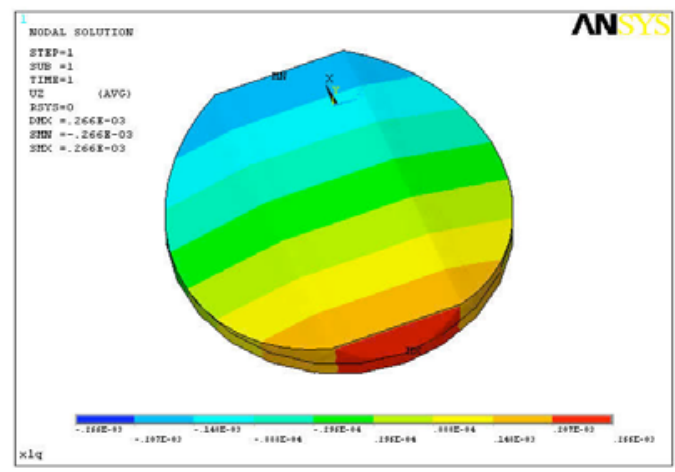

Fig. (20). The transformation of the bracket top (longitudinal direction).

Fig. (20) and Fig. (21) show that the maximum transformation of the bracket in the longitudinal direction is $0.27 \mathrm{~mm}$. The dark blue area of the horizontal transformation is just the anchored point of the towing steel strand. The area can be named towing area. So the loading areas are classified as bearing area, secure area and towing area according to the stress state and function of each part of the bracket, as is shown in Fig. (22). 


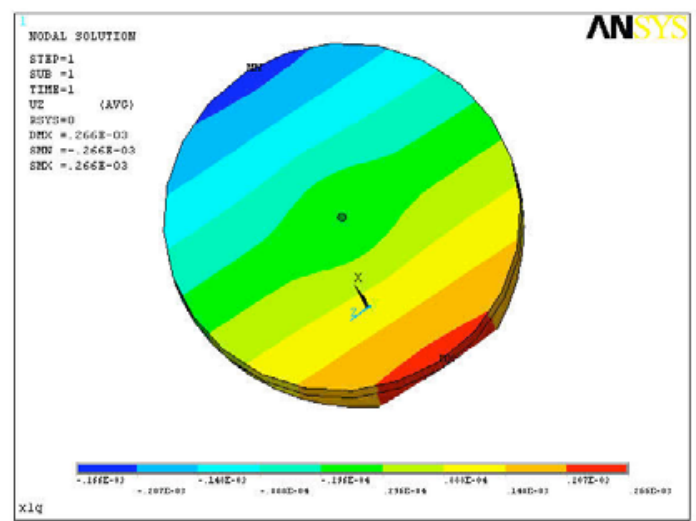

Fig. (21). The transformation of the bracket bottom (longitudinal direction).

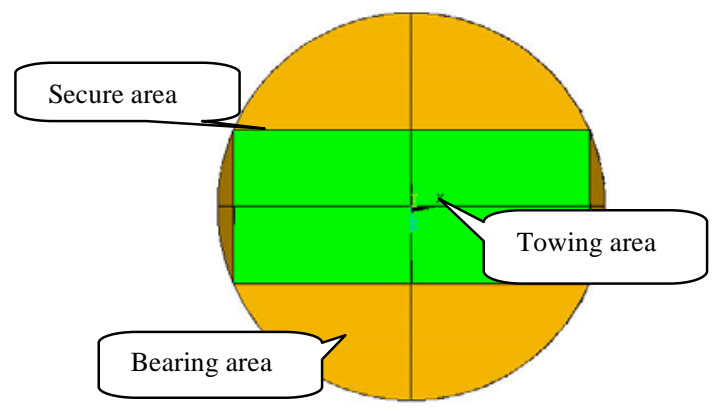

Fig. (22). Areas classified chart of the bracket.

\section{CONCLUTION}

Rotating construction is usually used in cable-stayed bridge crossing the railway. The construction technology of large tonnage concrete cable-stayed bridge is complex. Its structure form, boundary condition, material character and load form changes as time changes. Therefore as the key part of the rotating progress of Suifen River bridge, the bracket must be calculated and analysed particularly so as to get the main conclusion. First, the overall bracket structure mainly presents compressive stress state except individual points in the common influence of gravity, traction and prestress. Second, the whole stress level of bracket structure is very low when only consider the effect of traction. Third, under the effect of prestress, the bracket structure presents a huge pressure stress in horizontal direction to prevent accidental tilt in the rotating process.

\section{CONFLICT OF INTEREST}

The authors confirm that this article content has no conflict of interest.

\section{ACKNOWLEDGEMENTS}

This research was supported by the Fundamental Research Funds for the Central Universities (No. 2572015ET01) funded by Ministry of Finance, Education of the People's Republic of China and Heilongjiang Postdoctoral Grant (No. LBH-Z14013) funded by Heilongjiang provincial government.

\section{REFERENCES}

[1] J. Zhang and T. E. El-Diraby, "Constructability analysis of the bridge superstructure rotation construction method in China", Journal of Construction Engineering and Management, vol. 132, no. 4, pp. 353-362, April 2006.

[2] H. T. Shang, "Study on application of horizontal rotatio-n method in railway bridge construction", Journal of Railway Engineering Society, yol. 30, no. 1, pp. 29-34+84, January 2013.

[3] M. H. Olya and H. Fazlollahtabar, "Finding Shortest Path in a Combined Exponential -Gamma-Normal Probability Distribution Arc Length", Advances in Industrial Engineering and Management, vol. 3, no. 4, pp. 35-44, 2014. doi:10.7508/AIEM-V3-N4-3544

[4] K. Sulata, "Plastic rotation of an RCC T-beam bridge girder under the combined influence of flexure and torsion", Journal of Bridge Engineering, vol. 12, no. 1, pp. 21-30, 2007.

[5] L. C. Jiang and R. Gao, "Deformation monitoring during removal of the supporting of T-type rigid frame bridge constructed by rotation method", International Symposium on Archimedes Bridge, vol. 4, pp. 355-360, 2010.

[6] J. Y. Tong and Z. J. Zheng, "Simulation calculation of rotation platform piers of Gusaoshu Road Viaduct in Wuhan City", Bridge Construction, vol. 43, no. 2, pp. 64-69, April 2013. 